\title{
POWER, TIME, AND COST
}

David Braybrooke makes two criticisms of my theory of social power, ${ }^{1}$ one that deals with the time of power and one that concerns the relation between power and cost. In his first criticism he points out that, according to my analysis, Richard Nixon had the power, in 1940, to nominate Burger for Chief Justice in 1970, and a certain twelve-year old boy may today have the power to hit the first home run of the 1990 season. ${ }^{2}$ Braybrooke finds these consequences of the theory unacceptable. These agents may have the ability to acquire the indicated powers at these times, he argues, but they do not (yet) have these powers.

To deal with these examples adequately, we must distinguish two uses of 'power'. First, we sometimes use the term to refer to a particular kind of resource, (legal) competence, or skill, as when we speak of the power of the veto, the power of attorney, or a hypnotic power. In this use, 'power' frequently occurs as a count-noun, as in 'the powers of the President'. Now in this sense of the term there is a legitimate distinction between the possession of a power and the ability to acquire this power. A lawyer may have the ability to persuade a client to grant him the power of attorney; but the lawyer's persuasive ability is not the same as the power of attorney. Similarly, someone may have the ability to acquire the powers of the President, but this ability must not be identified with the powers of the President. In 1940 Richard Nixon may have had the ability to acquire the powers of the President some twenty-eight years later. But it does not follow that he had the powers of the President (including the power to nominate Supreme Court Justices) in 1940. I suspect that it is this sort of consideration that leads Braybrooke to deny that Richard Nixon had the power, in 1940, to nominate Burger for Chief Justice in 1970.

There is another kind of construction in which 'power' appears, however, which behaves somewhat differently. This second kind of construc- 
tion does not identify any particular kind of resource or competence. It merely asserts that an agent has some resources (of unspecified kinds) that suffice for obtaining a certain outcome, or for affecting a certain issue. The time of the power, in this kind of construction, may be different from (specifically, earlier than) the time of the outcome or issue. The expression I employed in my paper - viz., ' $S$ has power, at $t_{1}$, with respect to issue $E$ at $t_{n}{ }^{\prime}$ - is such a construction. Another, more familiar, construction of this sort is: 'It is in $S$ 's power, at $t$, to bring it about that $e$ occurs at $t$ '. For example, 'It is in my power now to throw a party tomorrow night'.

Now in this second use of 'power', it is not at all clear that there is a distinction between having power and having the ability to acquire it. On the contrary, I believe that constructions of this second sort exhibit what I shall call a 'de-nesting' property. When there are nested occurrences of the operator 'it is in $S$ 's power to bring it about that', one can preserve truth by deleting any internal occurrence of the operator. In other words, if it is in $S$ 's power at $t$ to bring it about that it is in $S^{\prime}$ s power at $t^{\prime}$ to bring it about that $e$ occurs at $t$ " (where the temporal indicators are in serial order), then it is in $S$ 's power at $t$ to bring it about that $e$ occurs at $t^{\prime \prime}$. For example, if it is in my power right now to bring it about that it is in my power tomorrow afternoon to throw a party tomorrow night, then it is in my power right now to throw a party tomorrow night. It is this sort of construction, bearing this de-nesting property, with which I was concerned in my paper. And in this use of 'power', it was in Richard Nixon's power, in 1940, to nominate Burger for Chief Justice in 1970. To be sure, nobody knew, or had reason to believe, in 1940, that this was in Richard Nixon's power. Even Richard Nixon did not know this. Nonetheless, it was in his power.

Braybrooke contends that $S$ has power, at $t$, over outcome $e$ at $t_{n}$ only if $S$ has appropriate resources at $t$. Presumably, he thinks that whatever resources Nixon had in 1940 were not appropriate for nominating a Chief Justice in 1970. And whatever resources the twelve-year old boy has now are not appropriate for hitting a home run in 1990. But when are resources 'appropriate'? Does one have to have all the resources at $t$ that will eventually be needed to obtain outcome $e$ at $t_{n}$ ? Certainly not.

Suppose my stock of liquor and food is thoroughly depleted, but I have plenty of money and ready access to liquor stores and supermarkets. I think my resources are sufficient that it would be correct to say that it is 
now in my power to throw a party tomorrow night. Clearly, I do not now have all the resources I will eventually need in order to throw a party. But as long as I have resources that suffice for obtaining other resources... that suffice for obtaining the outcome in question, then it is in my power now to bring about that outcome. I conclude, therefore, that it was in Nixon's power in 1940 to nominate Burger for Chief Justice in 1970. And it may be true that it is in the twelve-year old's power today to hit the first home run of the 1990 season.

Braybrooke claims that the set of people who have power, according to my analysis, is much larger than the set of people that social scientists who study power are interested in. This shows, he thinks, that I cast my net of power too wide. But it is easy to explain, on my theory, why social scientists may not be interested in some people who hold power (over important political issues) at one time or other. First, it is not always easy to tell who has power. A social scientist would not have shown much interest in Richard Nixon in 1940, for he would not have had evidence, in 1940, about the things that were in Richard Nixon's power at that time. Secondly, and more importantly, having power at one time over a given issue does not ensure having power at a later time over that same issue. In general, social scientists are interested in the people who have power over an issue at a time when the issue is being decided, or is about to be decided. There may be many people who once had power over this issue, but since they did not convert their resources into other relevant resources, or since they did not preserve their resources intact, they no longer have power at the time the issue is being decided. Such people will be of little or no interest to social scientists, despite the fact that they once had power. All this, of course, is fully compatible with my account of power.

Braybrooke's second criticism concerns my claim that power is inversely related to opportunity cost. On my view, the more valuable the things one would have to forego in order to obtain outcome $e$, the less is one's power over $e$. Braybrooke's first remark on this point betrays serious confusion. He writes: "There can hardly be any temptation to accept this contention as generally true. If $S$ 's total resources increase faster than the cost of getting $e$ or not-e, the increase in cost hardly reduces $S$ 's power to obtain one or the other."

The only way I can make sense of this remark is to construe resources and costs in terms of money. For example, if the cost of obtaining $e$ rises 
from $\$ 1000$ to $\$ 2000$, but $S$ 's income meanwhile rises from $\$ 15000$ to $\$ 20000$, the higher cost of obtaining $e$ does not reduce $S$ 's power over it. The trouble with this point is that $m y$ notion of cost requires measurement in utility, not money. In the case described, there is no increase in cost as measured in utility. In the second situation, as compared with the first, $S$ would have more money left over after obtaining $e$. Hence, obtaining $e$ in the second situation would involve fewer foregone opportunities, and hence less foregone utility, than in the first situation. It follows, on my account, that he has more power in the second situation than in the first, just as one would intuitively expect. Braybrooke might reply that his quoted passage refers to cost as measured in foregone utility, not to cost as measured by the money price of $e$. If so, however, I see no sense at all that can be attached to the supposition that resources increase faster than cost. If opportunity cost is increasing in any amount, it follows that (relevant) resources must be declining.

Braybrooke not only disagrees with the idea that power is inversely related to cost, but thinks this betrays "a lack of due appreciation for commonplaces in economics". If Braybrooke were right about this, we should certainly be surprised if any competent economist would agree with the idea. But the idea that power and opportunity cost are inversely related was introduced into the (recent) literature by a well-known economist, John C. Harsanyi, ${ }^{3}$ as I indicated in my paper. Braybrooke's comment suggests that it is he who is ignorant of the work of economists on the topic of power.

Nor is it recent writers only who have held a view of power that is similar, in the respect under discussion, to mine. Two classical philosophers, Plato and Hume, also espoused this conception, at least in embryo form. In his Treatise of Human Nature, Hume writes:

But according to common notions a man has no power, where very considerable motives lie betwixt him and the satisfaction of his desires, and determine him to forbear what he wishes to perform. I do not think I have fallen into my enemies power, when I see him pass me in the streets with a sword by his side, while I am unprovided of any weapon. I know that the fear of the civil magistrate is as strong a restraint as any of iron, and that I am in as perfect safety as if he were chain'd or imprison'd. But when a person acquires such an authority over me, that not only there is no external obstacle to his actions; but also that he may punish or reward me as he pleases, without any dread of punishment in his turn, I then attribute a full power to him, and consider myself as his subject or vassal. ${ }^{4}$ 
Plato makes some similar observations in the Gorgias, employing an almost identical example. That these two philosophers agree with me on this question does not show that we are right, but it strongly suggests that the thesis in question is not an 'aberration', as Braybrooke calls it.

We should concede to Braybrooke, however, that there is a sense of 'power' which ignores considerations of cost. A distinction may be drawn, then, between a cost and a non-cost sense of 'power'. These senses parallel the cost and non-cost senses of 'can' and 'able' that I discussed in Chapter 7 of my book $A$ Theory of Human Action. ${ }^{5}$ The first three sections of my paper on power were devoted, in effect, to the non-cost sense of 'power', though I did not formulate the matter in these terms.

It must be granted that the cost sense of 'power' tends to be invoked only when fairly substantial costs are involved. It is not surprising, therefore, that we would not say that Nixon's power to choose Agnew as his running-mate in 1972 is not diminished by the fact that this choice would affect James Reston's endorsement. Here we stick to the non-cost sense of 'power'. But suppose that Agnew had been indicted, in the summer of 1972, for (earlier) financial dealings in Maryland. Isn't it easy to imagine Nixon saying - privately, if not publicly - that he is 'powerless' to retain Agnew on the ticket? How could this remark be accounted for on the non-cost sense of 'power'? Admittedly, this statement would be a hyperbole even on the cost sense of 'power'. For if we stick to utilities having finite values, no amount of cost can completely eliminate power. But some explanation of this common hyperbole must be given. If the non-cost sense of 'power' (or of 'can' and 'able') were the only sense of 'power', it would be quite inexplicable how this sort of hyperbole should ever have obtained currency. My reconstruction of ordinary discourse is to suppose that cost affect degrees of power, but that people allow themselves to talk of 'complete' powerlessness by way of exaggeration.

For further illustration of the cost sense of 'power' in the social and political arena, consider the degree of power of a group of Blacks, who wish to influence legislation. There may be a set of sequences of action available to them that would secure their preferred outcome. But these actions may require unusual sacrifice, including great physical inconvenience, harm to their persons, danger to their freedom and employment security, etc, Other groups may be in a position to influence comparable legislation with far less effort and sacrifice. Surely these factors are crucial 
in the assessment of the Blacks as having relatively little power vis-à-vis the issue in question.

Braybrooke suggests that opportunity cost is relevant only to 'total' power, not to power with respect to a single outcome or issue. As long as $S$ has the resources to obtain outcome $e$, his power over $e$ is unaffected by the other events that would be foregone or incurred as a by-product of obtaining $e$. This, I believe, is a mistake. A person's power over a single outcome or issue is affected by the interconnection between obtaining this outcome and the occurrence of other events.

The point is quite clear in Hume's example. The extent of my enemy's power over me is not simply a function of his ability - in the non-cost sense of 'ability' - to do me physical harm. It is also a function of his ability or inability to harm me with impunity. To the extent that he values his own life and liberty, his inability both to harm me and to avoid a sanction affects, i.e., reduces, his power over me.

Another useful illustration concerns the relative power of a super-ordinate and a sub-ordinate. This example is borrowed from Harsanyi, who in turn credits it to Jacob Marschak (another prominent economist!). An employer has a secretary compile various reports, according to specific instructions. These reports are then used as the basis for an important decision. In the non-cost sense of 'power', the secretary has significant power over the decision, since omission or doctoring of pieces of information would affect the outcome substantially. Indeed, if we are restricted to the non-cost sense of 'power', the secretary may turn out to have more power than the employer with respect to this decision. But surely this is a misleading assessment of their relative power on this decision. The way to obtain a proper assessment of their relative power - one which rates the employer's power as greater than the secretary's - is to invoke the notion of cost. The secretary is in a position to affect the outcome only by doing things that endanger his or her continued employment. To the extent that the retention of that job is substantially valued, the cost of influencing the decision is substantial, and the secretary's power is correspondingly diminished. Note, however, that if it is the secretary's last day on the job, and if he or she has no need or interest in a good recommendation from the employer for future jobs, one's intuition suggests that the secretary's power is not insignificant on this issue. For in this case, the prospective cost of affecting the decision is very little. 
Braybrooke takes exception to my further contention that power is inversely related to the degree of desire that is needed to obtain the outcome in question. So let me comment on this contention as well. Braybrooke is right in saying that, in the main, this contention is derivative from the contention about power and cost. The more costly an outcome, the more it would have to be desired before the agent would act so as to obtain it. It should be noted, however, that the introduction of degrees of desire is necessitated by the theory as a whole. The central theme of the analysis is to account for power in terms of counterfactual suppositions about various agents' desires vis-à-vis the issue in question. It is assumed that such desires influence actions which in turn may influence the outcome of the issue. Now the actions one performs are a function not merely of whether or not one wants a particular outcome, but of how much one wants it. Thus, if our counterfactuals are to have determinate truth-values, we must introduce degrees of desire. Once degrees of desire are introduced, it is natural to correlate them with power.

There is independent support, however, for the correlation between power and degrees of desire. Consider the case of a dictator or Oriental potentate whose every whim is satisfied. One of the reasons we count him as so powerful is that even his whims - that is, even the things he has ever so slight a desire for - are satisfied. When we compare his power with respect to a given issue with someone else's power over a comparable issue, we find that the potentate will get his preferred outcome even if his preference is very slight. By contrast, an ordinary person would get his preferred outcome only if he preferred it strongly enough to warrant the effort and difficulty of getting it. The contrast lies in the degree of effort and/or difficulty that the respective agents require. The potentate's power is so great that very little effort or difficulty is encountered, and this is reflected in the degree of desire that would suffice for satisfaction.

Despite all of these arguments, I must remind the reader that I am not completely satisfied with the account I have given of the relationship between power and cost. Indeed, I expressed my reservations in the earlier paper at the end of my discussion of cost. I continue to believe, however, that only some reference to cost - along the general lines I have suggested - can account for the sorts of cases that $I$ have adduced. 


\section{NOTES}

1 See 'Two Blown Fuses in Goldman's Analysis of Power', Philosophical Studies 24 (1973) 369-377; 'Toward a Theory of Social Power', Philosophical Studies 23 (1972) 221-268.

2 Braybrooke neglects the fact that the concept I analyze concerns power with respect to issues, not outcomes or events. I ignore this point, however, because his criticisms could be reformulated to fit my terminology. Moreover, I have now switched my own terminology, and I wish to use 'power' in connection with outcomes and 'control' in connection with issues. (Cf. 'On the Measurement of Power', The Journal of Philosophy, forthcoming.) In this paper I shall speak both of power over issues and power over outcomes.

Another error in Braybrooke's discussion is more significant. He claims that, on my analysis, Hubert Humphrey, and perhaps thousands or millions of other people, also had the power, in 1940, to nominate Burger for Chief Justice in 1970. This is doubtful even for Hubert Humphrey, and almost certainly false for practically everyone else. This assumes, of course, that we are talking about what I call 'individual power', which is clearly what Braybrooke had in mind.

3 'Measurement of Social Power, Opportunity Costs, and the Theory of Two-Person Bargaining Games', Behavioral Science 7 (1962) 67-80.

4 Selby-Bigge edition, Clarendon Press, Oxford, p. 312. I am indebted to Charles Stevenson for calling my attention to this passage.

5 Prentice-Hall, Englewood-Cliffs, N.J., 1970. See pp. 209-212. 